\title{
Perilaku penggunaan gadget dengan kualitas tidur pada remaja
}

\author{
Umi Romayati Keswara ${ }^{1}$, Novrita Syuhada ${ }^{2}$, Wahid Tri Wahyudi ${ }^{3}$
}

\author{
${ }^{1}$ Akademi Keperawatan Malahayati Bandar Lampung. Email: romayatiumi@yahoo.com \\ 2Puskesmas Poncowati Kabupaten Lampung Tengah. Email: novritasyuhada79@gmail.com \\ 3 Program Studi Ilmu Keperawatan Universitas Malahayati Bandar Lampung. \\ Email : wahid@malahayati.ac.id
}

\section{Abstract \\ Electronic gadgets, psychological behavior and quality of sleep among adolescent}

Background: In the development stage, adolescents are faced with problems of health problems including poor sleep quality. Globally, the prevalence of sleep quality disorders in the world varies from $15.3 \%$ to $39.2 \%$. Data in Indonesia shows that most of the quality of sleep in adolescents is less than $63 \%$. Poor quality of sleep can harm health. Factors that can cause poor sleep quality include the use of gadgets, where $80 \%$ say using gadgets $>4$ hours 17 minutes a day.

Purpose: Known the electronic gadgets, psychological behavior and quality of sleep among adolescent.

Methods: The type of research used in this study was quantitative. The design of this study used analytics. The research subjects were class $X$ and XI students at SMKN 1 Terbanggi Besar, Central Lampung, totaling 119 people. Collect data with the Pittsburgh Sleep Quality Index (PSQI) questionnaire and Smartphone Addiction Scale (SAS). The statistical test uses the chi-square test.

Results: Univariate analysis was obtained by the majority of respondents who had bad behavior in using gadgets, as many as 68 people (57.1\%) and most respondents had poor sleep quality, as many as 77 people (64.7\%). Analysis data resulted $p$-value $=0,000$ and $O R=4,696$.

Conclusion: There were the electronic gadgets, psychological behavior and quality of sleep among adolescent. The advice is to increase health promotion counseling about sleep patterns and the excessive use of gadgets, and for schools to set regulations on the ban on the use of gadgets in-class hours.

\section{Keywords : Quality of Sleep, Gadgets, Adolescent; Psychological; Behavior}

Pendahuluan: Dalam tahap perkembangannya, remaja dihadapkan pada masalah-masalah kesehatan diantaranya kualitas tidur yang buruk. Secara global menunjukkkan prevalensi gangguan kualitas tidur di dunia bervariasi mulai $15,3 \%-39,2 \%$. Data di Indonesia menunjukan sebagian besar kualitas tidur pada remaja kurang terpenuhi yaitu sebanyak $63 \%$. Buruknya kualitas tidur dapat menimbulkan dampak negatif bagi kesehatan. Faktor yang dapat menyebabkan kualitas tidur yang buruk diantaranya adalah penggunaan gadget, dimana $80 \%$ menyatakan meggunakan gadget $>4$ jam 17 menit dalam sehari.

Tujuan: Diketahui hubungan perilaku penggunaan gadget dengan kualitas tidur pada remaja.

Metode: Jenis penelitian yang digunakan dalam penelitian ini adalah kuantitatif dengan rancangan menggunakan analitik. Subyek penelitian yaitu siswa kelas X dan XI di SMKN 1 Terbanggi Besar Lampung Tengah, yang berjumlah 119 responden. Cara pengambilan data dengan kuesioner Pittsburgh Sleep Quality Indeks (PSQI) dan Smartphone Addiction Scale (SAS). Uji stastistik menggunakan uji chi-square.

Hasil: Sebagian besar responden memiliki perilaku penggunaan gadget yang tidak baik, yaitu sebanyak 68 orang $(57,1 \%)$ dan sebagian besar responden memiliki kualitas tidur yang buruk, yaitu sebanyak 77 orang $(64,7 \%)$. Hasil uji statistik diperoleh $p$-value $=0,000$ dan $\mathrm{OR}=4,696$.

Simpulan: Ada hubungan perilaku penggunaan gadget dengan kualitas tidur pada remaja. Perlu lebih ditingkatkannya promosi kesehatan konseling tentang pola tidur dan dampak penggunaan gadget secara berlebihan, serta bagi pihak sekolah dapat menetapkan peraturan tentang larangan penggunaan gadget di jam pelajaran.

Kata Kunci: Kualitas Tidur; Gadget; Perilaku Remaja 
Perilaku penggunaan gadget dengan kualitas tidur pada remaja

\section{PENDAHULUAN}

Remaja adalah aset masa depan sebuah bangsa, sehingga masa depan bangsa akan ditentukan oleh remaja saat ini. Masa remaja (adolescence) merupakan masa dimana terjadi perpindahan masa kanak-kanak menuju dewasa. Remaja merupakan suatu tahap perkembangan yang ditandai dengan perubahan-perubahan fisik umum serta perkembangan kognitif dan sosial (Potter, \& Perry, 2010; Syamsoedin, Bidjuni, \& Wowiling, 2015).

Dalam tahap perkembangannya, remaja dihadapkan pada masalah-masalah kesehatan. Masalah kesehatan termasuk masalah yang berkaitan dengan organ reproduksi (seksual), dimana mereka sudah mencapai kematangan seksual yang menyebabkan dorongan untuk pemuasan kebutuhan seksual diluar pernikahan. Kemudian masalah psikologis juga dapat terjadi pada remaja diantaranya kenakalan (deliquency) pada remaja akibat kondisi konflik dalam usaha pencarian identitas diri. Seringkali remaja terlibat dalam geng-geng, dimana mereka akan saling memberi dan mendapat dukungan mental (Hidayat, 2014; Choirul, 2017).

Tugas perkembangan pada masa remaja yang disertai dengan perkembangan kemampuan intelektual, stres dan harapan baru yang dialami oleh remaja membuat mereka rentan terhadap gangguan, baik dalam bentuk gangguan mental dan gangguan perilaku (Pribadi, Utami, \& Marliyana, 2019).

Masalah kesehatan remaja lainnya yang tidak kalah penting adalah kurangnya pemenuhan kualitas tidur pada remaja. Tidur merupakan suatu keadaan berulang-ulang, perubahan status kesadaran yang terjadi selama periode tertentu. Fungsi tidur sangat penting untuk pemenuhan kognitif remaja. Selama tidur gelombang rendah yang dalam, tubuh melepaskan hormone pertumbuhan manusia untuk memperbaiki dan memperbaharui sel epitel dan khusus seperti sel otak. Tidur juga berhubungan dengan perubahan dalam aliran darah serebral, peningkatan aktivitas kortikal, peningkatan konsumsi oksigen, dan pelepasan epinefrin (Syamsoedin, Bidjuni, \& Wowiling, 2015). Setelah seharian beraktivitas, tidur dapat memulihkan dan mengistirahatkan fisik, mengurangi stress maupun kecemasan serta dapat meningkatkan kemampuan dan daya konsenterasi. Apabila kualitas tidur tidak terpenuhi atau mengalami gangguan dapat mempengaruhi kebutuhan remaja yang lain (Mubarak, \& Chayatin, 2008; Khusnal, 2017).

Prevalensi gangguan kualitas tidur pada remaja dari berbagai penelitian menunjukan hasil yang bervariasi, didapatkan 21,2\% anak remaja di Beijing mengalami gangguan kualitas tidur. Siswa SMP dan SMU menunjukkkan prevalensi gangguan kualitas tidur bervariasi mulai 15,3\% hingga 39,2\% (Liu, Ma, Wang, Jiang, Rao, Lu, \& Teng, 2005; Ohida, Osaki, Doi, Tanihata, Minowa, Suzuki, \& Kaneita, 2004; Azmi, \& Erkadius, 2017).

Berdasarkan data di Indonesia, masih jarang penelitian epidemiologi yang dilakukan untuk mengetahui kualitas tidur pada remaja. Penelitian mengenai kualitas tidur dengan menggunakan metode Sleep Disturbances Scale for Children mendapatkan prevalensi kualitas tidur yang buruk (sebagian besar pada gangguan transisi tidurbangun) pada populasi kontrol adalah sebesar 73,4\% (Bruni, Ottaviano, Guidetti, Romoli, Innocenzi, Cortesi, \& Giannotti, 1996; Haryono, Rindiarti, Arianti, Pawitri, Ushuluddin, Setiawati, \& Sekartini, 2016; (Awwal, Hartanto, \& Hendrianingtyas, 2015). Selain itu, sebagian besar kualitas tidur pada remaja kurang terpenuhi $(<7$ jam setiap malamnya) yaitu sebanyak $63 \%$ (Khusnal, 2017).

Sering kurang terpenuhi kualitas tidur remaja disebabkan pada remaja memiliki pola yang berbeda dibandingkan usia lainnya. Hal ini akibat dari pada masa akhir pubertas, remaja mengalami sejumlah perubahan yang seringkali mengurangi waktu tidur. Remaja lebih sering tidur waktu malam dan bangun lebih cepat karena tuntutan sekolah, sehingga remaja seringkali mengantuk berlebihan pada siang hari (Syamsoedin, Bidjuni, \& Wowiling, 2015).

Dampak kualitas tidur yang buruk antara lain akan mengalami berbagai hal negatif diantaranya rentan mengalami kecelakaan, masalah kesehatan fisik, gangguan memori dan pembelajaran, beresiko tinggi mengalami obesitas serta masalah kesehatan mental (Huda, 2016; Khusnal, 2017).

Salah satu dai faktor yang menyebabkan remaja mengalami kualitas tidur yang buruk diantaranya adalah perubahan gaya hidup termasuk penggunaan gadget. Dibandingkan faktor lain, penggunaan gadget dikalangan remaja sudah menjadi faktor yang tidak dapat dihindarkan. Setidaknya 30 juta anak-anak dan remaja di

Umi Romayati Keswara' Akademi Keperawatan Malahayati Bandar Lampung' Email: romayatiumi@yahoo.com

Novrita Syuhada ${ }^{2}$ Puskesmas Poncowati Kabupaten Lampung Tengah. Email: novritasyuhada79@gmail.com

Wahid Tri Wahyudi ${ }^{3}$ Program Studi llmu Keperawatan Universitas Malahayati Bandar Lampung.

Email : wahid@malahayati.ac.id 
Indonesia merupakan pengguna gadget (internet dan media digital) yang saat ini menjadi pilihan utama saluran komunikasi yang mereka gunakan. Hasil studi menemukan bahwa $80 \%$ responden yang disurvei merupakan pengguna gadget (internet), dengan bukti kesenjangan digital yang kuat antara mereka yang tinggal di wilayah perkotaan dan lebih sejahtera di Indonesia, dengan mereka yang tinggal di daerah perdesaan (kurang sejahtera) (Sari, llyas, \& Ifdil, 2017). Sekelompok remaja yang sedang berkumpul bersama dalam satu tempat, namun frekuensi mereka berbicara lebih rendah dibanding dengan menggunakan smartphone-nya masing-masing. Pengguna internet di Indonesia hingga saat ini telah mencapai 82 juta orang. Melihat capaian tersebut, Indonesia berada pada peringkat ke-8 di dunia. Berdasarkan jumlah pengguna internet tersebut, $80 \%$ di antaranya adalah remaja berusia 15-19 tahun (Broto, 2014).

Dampak penggunaan gadget antara lain yaitu pada remaja menggunakan media sosial didalam gadget mereka, sehingga menimbulkan lebih banyak waktu yang digunakan untuk bermain gadget (Damayanti, 2017). Pemakaian smartphone dalam waktu lama ini menyebabkan mereka memerlukan sekitar 60 menit lebih lama untuk tertidur dari pada waktu biasanya. Dengan demikian, para remaja ini akan cenderung tidur terlambat dari biasanya. Kecanggihan dan kemudahan yang disediakan smartphone saat ini menyebabkan banyak orang terperangkap untuk selalu beraktifitas menggunakan smartphone (Mawitjere, Onibala, \& Ismanto, 2017).

Berdasarkan dari hasil wawancara terhadap 10 remaja di SMKN Lampung Tengah, sebanyak 7 orang $(70 \%)$ mengalami tanda-tanda kualitas tidur yang buruk, yaitu konjungtiva kemerahan, mata terlihat cekung, kantuk yang berlebihan (sering menguap), tidak mampu untuk berkonsentrasi dan sering merasa pusing. Selain itu, dari 10 remaja, sebanyak 8 orang $(80 \%)$ menyatakan meggunakan gadget $>4$ jam 17 menit dalam sehari.

\section{METODE PENELITIAN}

Jenis penelitian kuantitatif. Rancangan analitik observasional dengan pendekatan secara cross sectional. Penelitian ini sudah lulus kelaikan etik dari Komisi Etik Penelitian Kesehatan Universitas Malahayati dan dilaksanakan di SMKN 1 Terbanggi Besar Lampung Tengah pada Mei 2019. Populasi seluruh remaja kelas $X$ dan $X I$ sebanyak 167 siswa, dengan sampel sebanyak 119 sampel. Teknik pengambilan sampel menggunakan proportional random sampling.

Alat pengumpulan data dengan instrumen baku yaitu Pittsburgh Sleep Quality Indeks (PSQI) sebanyak 9 pertanyaan untuk mengukur kualitas tidur dan kuesioner Smartphone Addiction Scale (SAS) untuk mengetahui penggunaan gadget sebanyak 10 soal.

Pada penelitian ini, data diambil dan dikumpulkan langsung dari responden dengan melakuan pengisian kuesioner oleh responden yang dibagikan dan diisi pada hari itu. Kemudian hasil perolehan dicatat dan didokumentasikan untuk selanjutnya dilakukan pengolahan data. Dalam analisis ini menggunakan pengujian statistik chi-square dengan taraf yang digunakan adalah $5 \%$ atau $p$-value 0,05 .

\section{HASIL}

Tabel 1. Distribusi Frekuensi Perilaku Penggunaan Gadget N = 119

\begin{tabular}{ccc}
\hline $\begin{array}{c}\text { Prilaku } \\
\text { Penggunaan } \\
\text { Gadget }\end{array}$ & Frekuensi (F) & Presentase (\%) \\
\hline Baik & 51 & 42,9 \\
Tidak Baik & 68 & 57,1 \\
Total & 119 & 100 \\
\hline
\end{tabular}

Berdasarkan tabel 1 diatas dapat diketahui bahwa sebagian besar responden memiliki perilaku penggunaan gadget yang tidak baik, yaitu sebanyak 68 orang $(57,1 \%)$.

Umi Romayati Keswara' Akademi Keperawatan Malahayati Bandar Lampung: Email: romayatiumi@yahoo.com Novrita Syuhada ${ }^{2}$ Puskesmas Poncowati Kabupaten Lampung Tengah. Email: novritasyuhada79@gmail.com Wahid Tri Wahyudi ${ }^{3}$ Program Studi llmu Keperawatan Universitas Malahayati Bandar Lampung.

Email : wahid@malahayati.ac.id 
Tabel 2. Distribusi Frekuensi Kualitas Tidur N = 119

\begin{tabular}{ccc}
\hline Kualitas Tidur & Frekuensi (F) & Presentase (\%) \\
& & \\
\hline Baik & 42 & 35,3 \\
Buruk & 77 & 64,7 \\
Total & $\mathbf{1 1 9}$ & $\mathbf{1 0 0}$ \\
\hline
\end{tabular}

Berdasarkan tabel 2 diatas dapat diketahui bahwa sebagian besar responden memiliki kualitas tidur yang buruk, yaitu sebanyak 77 orang $(64,7 \%)$.

Tabel 3. Hubungan Perilaku Penggunaan Gadget Dengan Kualitas Tidur N $=119$

\begin{tabular}{|c|c|c|c|c|c|c|c|c|}
\hline \multirow{3}{*}{$\begin{array}{l}\text { Perilaku } \\
\text { Penggunaan } \\
\text { Gadget }\end{array}$} & \multicolumn{4}{|c|}{ Kualitas Tidur } & \multirow{2}{*}{\multicolumn{2}{|c|}{ Total }} & \multirow{3}{*}{$p$-value } & \multirow{3}{*}{$\begin{array}{c}\text { OR } \\
95 \% \mathrm{Cl}\end{array}$} \\
\hline & \multicolumn{2}{|c|}{ Baik } & \multicolumn{2}{|c|}{ Buruk } & & & & \\
\hline & $\mathrm{n}$ & $\%$ & $\mathrm{n}$ & $\%$ & $\mathbf{N}$ & $\%$ & & \\
\hline Baik & 28 & 54,9 & 23 & 45,1 & 51 & 100 & \multirow{3}{*}{0,000} & 4,696 \\
\hline Tidak Baik & 14 & 20,6 & 54 & 79,4 & 68 & 100 & & $(2,097-$ \\
\hline Total & 42 & 35,3 & 77 & 64,7 & 119 & 100 & & $10,514)$ \\
\hline
\end{tabular}

Berdasarkan tabel 3 diatas dapat dilihat bahwa dari 51 responden dengan perilaku penggunaan gadget baik, sebanyak 28 orang $(54,9 \%)$ memiliki kualitas tidur baik sedangkan sebanyak 23 orang $(45,1 \%)$ memiliki kualitas tidur buruk. Selain itu, dari 68 responden dengan perilaku penggunaan gadget tidak baik, sebanyak 14 orang $(20,6 \%)$ memiliki kualitas tidur baik sedangkan sebanyak 54 orang $(79,4 \%)$ memiliki kualitas tidur buruk.

Hasil analisis menggunakan chi-square, didapatkan $p$-value $=0,000$, sehingga $p$-value $<a(0,000<0,05)$, maka Ha diterima. Jadi dapat disimpulkan terdapat hubungan perilaku penggunaan gadget dengan kualitas tidur pada remaja. Selain itu, dari perhitungan didapatkan pula nilai odds ratio $(O R)=4,696$, maka dapat disimpulkan bahwa remaja dengan perilaku penggunaan gadget tidak baik, memiliki risiko 4,696 kali mengalami kualitas tidur yang buruk dibanding dengan bahwa remaja dengan perilaku penggunaan gadget baik.

\section{PEMBAHASAN}

\section{Perilaku Penggunaan Gadget}

Berdasarkan hasil penelitian diperoleh bahwa sebagian besar responden memiliki perilaku penggunaan gadget yang tidak baik, yaitu sebanyak 68 orang $(57,1 \%)$.

Sesuai dengan teori bahwa gadget diciptakan dengan berbagai aplikasi yang dapat menyajikan berbagai media berita, jejaring sosial, hobi, bahkan hiburan (Widiawati, \& Sugiman, 2014; Arifin, \& Rahmadi, 2017).

Sejalan dengan penelitian sebelumnya yang menyebutkan sebanyak $51 \%$ remaja menggunakan gadget dalam ketegori sedang (Khusnal, 2017). Selain itu hasil penelitian lainnya memperlihatkan bahwa sebanyak $28,2 \%$ remaja menggunakan gadget tellau lama yakni > 11 jam/hari (Mawitjere, Onibala, \& Ismanto, 2017).

Menurut pendapat peneliti sebagian besar responden memiliki perilaku penggunaan gadget yang tidak baik disebabkan karena gadget telah mempengaruhi setiap aspek responden dimana pada usia remaja tersebut mereka mulai diberi kepercayaan untuk memiliki gadget sendiri dan sebagian besar telah memiliki ketergantungan pada gadget. Ketergantungan gadget tersebut terus meningkat pada remaja sehingga mengganggu perencanaan pekerjaan yang seharusnya dilakukan karena terlalu asyik dalam menggunakan gadget, sehingga sampai kehilangan konsentrasi di kelas, saat melakukan tugas, atau saat bekerja karena kecanduannya kepada gadget. Remaja menjadikan gadget sebagai kebutuhan hingga mengakibatkan mereka sering lupa waktu dan melakukan aktivitas penggunaan gadget hingga larut malam misalnya mereka terus-menerus memeriksa gadget agar tidak ketinggalan percakapan antara orang lain di Twitter atau Facebook.

Umi Romayati Keswara' Akademi Keperawatan Malahayati Bandar Lampung Email: romayatiumi@yahoo.com Novrita Syuhada ${ }^{2}$ Puskesmas Poncowati Kabupaten Lampung Tengah. Email: novritasyuhada79@gmail.com Wahid Tri Wahyudi ${ }^{3}$ Program Studi llmu Keperawatan Universitas Malahayati Bandar Lampung.

Email : wahid@malahayati.ac.id 


\section{Kualitas Tidur}

Berdasarkan hasil penelitian diperoleh bahwa sebagian besar responden memiliki kualitas tidur yang buruk, yaitu sebanyak 77 orang $(64,7 \%)$.

Sesuai dengan teori bahwa sejumlah faktor mempengaruhi kuantitas dan kualitas tidur. Sering kali faktor tunggal tidak hanya menjadi penyebab masalah tidur. Faktor fisiologis, psikologis, dan lingkungan dapat mengubah kualitas dan kuantitas tidur antara lain: penyakit fisik; obat-obatan dan substansi; gaya hidup; stres emosional; lingkungan; latihan fisik dan kelelahan; asupan makanan dan kalori (Syamsoedin, Bidjuni, \& Wowiling, 2015).

Hasil penelitian ini sejalan dengan penelitian sebelumnya yang menunjukkan sebagian besar kurang terpenuhi yaitu sebanyak 32 siswa (63\%) (Khusnal, 2017). Selain itu, penelitian lainnya memperlihatkan bahwa sebanyak $74.4 \%$ remaja mengalami gangguan kualitas tidur ringan (Mawitjere, Onibala, \& Ismanto, 2017).

Menurut pendapat peneliti sebagian besar responden memiliki kualitas tidur yang buruk disebabkan karena berbagai faktor antara lain kebiasaan menggunakan gadget dimana sebagian besar remaja masih menggunakan gadget secara berlebihan dimana hal tersebut dapat mengganggu fikiran, konsenterasi, pekerjaan, dan mempengaruhi kehidupan sehari-hari sehingga dapat mengganggu kualitas tidur. Disamping itu kualitas tidur dapat juga disebabkan oleh faktor lainnya faktor lain misalnya lingkungan yang bising; latihan fisik dan kelelahan akibat aktivitas di sekolah.

\section{Hubungan Perilaku Penggunaan Gadget Dengan Kualitas Tidur}

Berdasarkan hasil penelitian diperoleh bahwa terdapat hubungan perilaku penggunaan gadget dengan kualitas tidur pada remaja dengan $p$-value $=0,000$ dan $\mathrm{OR}=4,696$.

Hasil penelitian ini sesuai dengan teori bahwa gadget bisa dibilang sudah menjadi gaya hidup mereka sehari-hari, bahkan remaja tidak bisa hidup dan terlepas dari gadget. Gaya hidup seseorang sangat berpengaruh terhadap pola tidur seseorang. Hal ini dikarenakan rutinitas seseorang di siang hari akan mempengaruhi istirahatnya pada malam hari (Huda, 2016; Khusnal, 2017)

Sejalan dengan penelitian terdahulu bahwa terdapat hubungan yang signifikan antara hubungan lama penggunaan gadget dengan kejadian insomnia pada siswa-siswi SMA dengan $(p$-value $=0,002)$ (Mawitjere, Onibala, \& Ismanto, 2017). Selain itu, penelitian lainnya diperoleh bahwa terdapat hubungan antara perilaku penggunaan gadget dengan kualitas tidur pada anak usia remaja dengan ( $p=0,048<0,05$ ) (Khusnal, 2017).

Menurut pendapat peneliti adanya hubungan perilaku penggunaan gadget dengan kualitas tidur pada remaja disebabkan karena penggunaan gadget terlebih saat malam hari akan menggangu jadwal tidur seseorang, selain itu jika terlalu lama bertatapan dengan layar gadget dalam waktu lama maka akan menimbulkan kesulitan untuk tertidur karena sinar biru yang menyerupai cahaya pada siang hari menyebabkan seseorang tetap terjaga, dimana tubuh akan sesorang akan mudah mengantuk jika dalam keadaan cahaya redup. Hal ini terlihat dari hasil penelitian dimana proporsi responden dengan perilaku penggunaan gadget baik cenderung memiliki kualitas tidur baik $(54,9 \%)$. Selain itu, responden dengan perilaku penggunaan gadget tidak baik cenderung memiliki kualitas tidur buruk $(79,4 \%)$. Selain itu, tidur berdekatan dengan gadget dapat mempengaruhi kualitas tidur dikarenakan pada saat malam hari gadget yang diletakan didekat tempat tidur, dalam keadaan aktif dapat berdering atau bergetar menandakan adanya notifikasi pesan dan sebagainya maka otak akan bersiaga untuk menerima stimulus dari luar yang berupa suara, cahaya, dan getaran dari gadget, selanjutnya otak mengirimkan sinyal tersebut sehingga menyebabkan remaja tetap terjaga dimalam hari. Kesadaran ini menyebabkan otak terus waspada tanpa kita sadari sehingga tidur berdekatan dengan gadget akan dapat mengurangi kualitas tidur.

Berdasarkan hasil penelitian didapatkan bahwa sebagian responden dengan perilaku penggunaan gadget baik namun memiliki kualitas tidur buruk $(45,1 \%)$. Hal ini dapat disebabkan karena faktor lain selain penggunaan gadget misalnya pada saat kondisi sakit yang diderita sehingga menyebabkan gangguan tidur pada remaja tersebut. Kondisi stres emosional misalnya yang berhubungan dengan pelajaran atau masalah keluarga juga akan memberi dampak yang jelas terhadap perubahan kualitas tidur remaja. Kemudian kondisi lingkungan fisik yang bising juga dapat menyebabkan remaja

Umi Romayati Keswara' Akademi Keperawatan Malahayati Bandar Lampung Email: romayatiumi@yahoo.com Novrita Syuhada ${ }^{2}$ Puskesmas Poncowati Kabupaten Lampung Tengah. Email: novritasyuhada79@gmail.com Wahid Tri Wahyudi ${ }^{3}$ Program Studi llmu Keperawatan Universitas Malahayati Bandar Lampung.

Email : wahid@malahayati.ac.id 
mengalami gangguan kualitas tidur. Selain itu, faktor kelelahan akibat aktifitas yang berlebihan misalnya yang berhubungan dengan kegiatan di sekolah dapat mengakibatkan remaja mengalami gangguan kualitas tidur. Kemudian berdasarkan hasil penelitian juga didapatkan bahwa sebagian responden dengan perilaku penggunaan gadget tidak baik namun memiliki kualitas tidur baik $(20,6 \%)$. Hal ini dapat disebabkan karena karena faktor lain selain penggunaan gadget misalnya walaupun responden merasa selalu memikirkan gadget saat melakukan tugas atau saat bekerja, terus-menerus memeriksa gadget agar tidak ketinggalan percakapan antara orang lain di Twitter atau Facebook, namun tetap memperhatikan jam tidur malam mereka.

\section{SIMPULAN}

Responden sebanyak 119 orang memiliki perilaku penggunaan gadget yang tidak baik, yaitu sebanyak 68 orang $(57,1 \%)$. Responden memiliki kualitas tidur yang buruk, yaitu sebanyak 77 orang $(64,7 \%)$. Terdapat hubungan perilaku penggunaan gadget dengan kualitas tidur pada remaja ( $p$-value $=0,000$ dan $\mathrm{OR}=4,696$ ).

\section{SARAN}

Remaja sebagai obyek penelitian yang menjadi pengguna gadget harus menjaga dan memperhatikan kualitas tidurnya agar tidak berpengaruh pada kesehatan fisik, tingkat emosi, konsentrasi, prestasi belajar ataupun masalah yang lebih serius.

\section{DAFTAR PUSTAKA}

Arifin, L. A., \& Rahmadi, F. A. (2017). Hubungan Tingkat Kecanduan Gadget dengan Prestasi Belajar Siswa Usia 10-11 Tahun (Doctoral dissertation, Faculty of Medicine).

Awwal, H., Hartanto, F., \& Hendrianingtyas, M. (2015). Prevalensi Gangguan Tidur Pada Remaja Usia 12-15 Tahun: Studi Pada Siswa SMP N 5 Semarang. Jurnal Kedokteran Diponegoro, 4(4), 873-880.

Azmi, S., \& Erkadius, E. (2017). Hubungan Kualitas Tidur dengan Tekanan Darah pada Pelajar Kelas 2 SMA Negeri 10 Padang. Jurnal Kesehatan Andalas, 6(2), 318-323.
Broto, G. S. D. (2014). Riset Kominfo dan UNICEF Mengenai Perilaku Anak dan Remaja Dalam Menggunakan Internet. Dalam https://kominfo. go. id/indeKanzul Ulum. php/content/detail/3834/Siaran+ Pers, (17-PIH).

Bruni, O., Ottaviano, S., Guidetti, V., Romoli, M., Innocenzi, M., Cortesi, F., \& Giannotti, F. (1996). The Sleep Disturbance Scale for Children (SDSC) Construct ion and validation of an instrument to evaluate sleep disturbances in childhood and adolescence. Journal of sleep research, 5(4), 251-261.

Choirul, M. C. (2017). Hubungan antara indeks kualitas tidur dengan prestasi belajar siswa.Jurnal Keperawatan, 8(2), 60-66.

Damayanti, R. A. M. (2017). Hubungan Penggunaan Gadget dengan Pencapaian Tugas Perkembangan Anak Usia Remaja Awal SDN di Kecamatan Godean (Doctoral dissertation, Fakultas Kedokteran dan IImu Kesehatan Universitas Muhammadiyah Yogyakarta).

Haryono, A., Rindiarti, A., Arianti, A., Pawitri, A., Ushuluddin, A., Setiawati, A., \& Sekartini, R. (2016). Prevalensi gangguan tidur pada remaja usia 12-15 tahun di sekolah lanjutan tingkat pertama. Sari Pediatri, 11(3), 149-54.

Hidayat, D. R. (2014). Ilmu Perilaku Manusia. Jakarta: CV. Trans Info Media.

Huda, N. (2016). 100 fakta seputar tidur yang perlu anda tahu. Jakarta: PT Elex Media Komputindo.

Khusnal, E. (2017). Hubungan Perilaku Penggunaan Gadget Dengan Kualitas Tidur Pada Anak Usia Remaja Di SMA Negeri 1 Srandakan Bantul (Doctoral Dissertation, Universitas' Aisyiyah Yogyakarta).

Liu, X., Ma, Y., Wang, Y., Jiang, Q., Rao, X., Lu, X., \& Teng, H. (2005). Brief report: an epidemiologic survey of the prevalence of sleep disorders among children 2 to 12 years old in Beijing, China. Pediatrics, 115(Supplement 1), 266-268.

Umi Romayati Keswara' Akademi Keperawatan Malahayati Bandar Lampung Email: romayatiumi@yahoo.com Novrita Syuhada ${ }^{2}$ Puskesmas Poncowati Kabupaten Lampung Tengah. Email: novritasyuhada79@gmail.com Wahid Tri Wahyudi ${ }^{3}$ Program Studi llmu Keperawatan Universitas Malahayati Bandar Lampung.

Email : wahid@malahayati.ac.id 
Mawitjere, O. T., Onibala, F., \& Ismanto, Y. A. (2017). Hubungan Lama Penggunaan Gadget Dengan Kejadian Insomnia Pada Siswa Siswi Di SMA Negeri 1 Kawangkoan. Jurnal Keperawatan, 5(1).

Mubarak, W. I., \& Chayatin, N. (2008). Buku ajar kebutuhan dasar manusia: Teori dan aplikasi dalam praktik. Jakarta: Media Aesculapius.

Ohida, T., Osaki, Y., Doi, Y., Tanihata, T., Minowa, M., Suzuki, K., \& Kaneita, Y. (2004). An epidemiologic study of self-reported sleep problems among Japanese adolescents. Sleep, 27(5), 978-985.

Potter, P. A., \& Perry, A. G. (2010). Fundamental of Nursing, Buku 1 Edisi 7. Penerjemah, Nggie, FA \& Albar Marina. Editor Hartanti Yayuk. Salemba Medika: Jakarta.
Pribadi, T., Utami, S., \& Marliyana, M. (2019). Bullying behavior among teenagers at junior high school lampung-indonesia. Malahayati International Journal Of Nursing And Health Science, 2(1), 32-40.

Sari, A. P., Ilyas, A., \& Ifdil, I. (2017). Tingkat Kecanduan Internet pada Remaja Awal. JPPI (Jurnal Penelitian Pendidikan Indonesia), 3(2), 110-117.

Syamsoedin, W. K. P., Bidjuni, H., \& Wowiling, F. (2015). Hubungan Durasi Penggunaan Media Sosial Dengan Kejadian Insomnia Pada Remaja Di SMA Negeri 9 Manado. Jurnal Keperawatan, 3(1).

Widiawati, I., \& Sugiman, H. (2014). Pengaruh Penggunaan Gadget Terhadap Daya Kembang Anak. Jakarta: Universitas Budi Luhur. Ejournal Keperawatan, 6, 1-6.

Umi Romayati Keswara' Akademi Keperawatan Malahayati Bandar Lampung Email: romayatiumi@yahoo.com Novrita Syuhada ${ }^{2}$ Puskesmas Poncowati Kabupaten Lampung Tengah. Email: novritasyuhada79@gmail.com Wahid Tri Wahyudi ${ }^{3}$ Program Studi llmu Keperawatan Universitas Malahayati Bandar Lampung.

Email : wahid@malahayati.ac.id 